\title{
Metastatic Esophageal Adenocarcinoma
}

National Cancer Institute

\section{Source}

National Cancer Institute. Metastatic Esophageal Adenocarcinoma. NCI Thesaurus. Code C156074.

An adenocarcinoma that arises from the esophagus and has metastasized to another anatomic site. 